Classification

Physics Abstracts

$68.65+\mathrm{g}$

\title{
Study of $\mathrm{FeCl}_{3}$ and $\mathrm{CoCl}_{2}$ graphite intercalation compounds reduced by heavy alkali metal vapour
}

\author{
Claire Hérold, Jean François Marêché and Guy Furdin \\ Laboratoire de Chimie Minérale Appliquée, U.R.A. C.N.R.S. $n^{\circ} 158$, Université de Nancy I, B.P. 239, \\ 54506 Vandoeuvre les Nancy Cedex, France
}

(Received October 28, 1991; accepted January 22, 1992)

\begin{abstract}
Résumé. - Dans cet article nous présentons les résultats de microscopie électronique à fond clair, de microdiffraction et de microanalyse obtenus sur des composés d'insertion du graphite avec $\mathrm{FeCl}_{3}$ et $\mathrm{CoCl}_{2}$ préparés à partir de monocristaux de graphite et réduits à température peu élevée par la vapeur de potassium, rubidium ou césium. Ces produits multiphasés contiennent des inclusions métalliques et de chlorures alcalins de 5 à $50 \mathrm{~nm}$, mais aussi du métal à l'état bidimensionnel. L'étude de la stabilité de ces phases en fonction de la température a été abordée.
\end{abstract}

\begin{abstract}
We present here direct imaging, microdiffraction and microanalysis results on $\mathrm{FeCl}_{3}$ and $\mathrm{CoCl}_{2}$ G.I.C. prepared using single crystals of graphite and further reduced at relatively low temperature by potassium, rubidium or cesium vapour. These products contain several phases: transition metal and alkali metal halide inclusions (size 5 to $50 \mathrm{~nm}$ ), and also two dimensional, intercalated transition metal. An initial study of the thermal stability of these phases was made.
\end{abstract}

\section{Introduction.}

Direct intercalation of transition metals into graphite has never succeeded to date. So, indirect intercalation of these elements has been studied. The most often used means is the reduction of intercalated transition metal halides. These chemical or electrochemical reactions usually give products containing several phases. When the reducing agent does not intercalate into graphite, the products resulting from the reduction are situated mainly at the edges of the particles. This has been evidenced in [10] where dispersions of transition metals obtained by reduction of metal halides by a suspension of $\mathrm{KC}_{8}$ in diglyme were submitted to various analytical techniques. No intercalation at all was noted. Reducing agents able to intercalate favor the formation of inclusions or intercalation products.

In this paragraph we will review the works including electron microscopy examination of reduced G.I.C. samples. Saunders and Fryer [1] reducing $\mathrm{G}-\mathrm{FeCl}_{3}$ compounds by lithium biphenyl obtained distorted and partly exfoliated particles containing many clusters ( $\alpha$ iron and $\mathrm{LiCl}$ ) and possibly some intercalated iron, the existence of which was deduced from Moiré fringes. Smith $e t$ 
al. [2] applied the same reducing agent to a series of intercalated transition halides ("Graphimets" from Ventron Corporation) (now Alfa Products, Johnson Matthey) and obtained products containing metal clusters, more or less oxidized on their surface, depending on the size (1 to $10 \mathrm{~nm}$ ) and metal. By electrochemical reduction of $\mathrm{G}-\mathrm{CoCl}_{2}$ and $\mathrm{G}-\mathrm{CuCl}_{2}, \mathrm{Nguessan}$ and Touzain [3] obtained a reticular distance of $557 \mathrm{pm}$ attributed to first stage graphite cobalt intercalation compound and clusters 10 to $250 \mathrm{~nm}$ in diameter. The same authors [4] compared X-ray diffraction and electron microdiffraction for their cobalt containing products. They proposed a commensurate $C_{2}$ Co structure with $I_{c}=1680 \pm 60 \mathrm{pm}$ and $\mathrm{A} / \mathrm{B} / \mathrm{C}$ stacking. Messaoudi et al and Kaiser et al. [5] reduced $\mathrm{G}-\mathrm{FeCl}_{3}$ and $\mathrm{G}-\mathrm{CoCl}_{2}$ compounds by potassium vapour at $300^{\circ} \mathrm{C}$ and obtained metallic clusters. They sized them using electron microscopy ( 30 to $35 \mathrm{~nm}$ ) and X-ray diffraction. They claimed that their clusters originated from the reduction of the intercalated islands. It has been shown by Mabchour et al. [6] that, in the case of the reduction of $\mathrm{G}-\mathrm{FeCl}_{3}$ compounds by potassium vapour, the size of the clusters is larger if the reduction temperature is higher. It was thus of interest to investigate the reduction of intercalated halides at the lowest possible temperature, and to extend the study to the heavier alkali metal vapours ( $\mathrm{Rb}$ and $\mathrm{Cs}$ ).

\section{Experimental.}

The starting material is constituted of Madagascar natural single crystals $10 \mu \mathrm{m}$ average diameter, $0.1 \mu \mathrm{m}$ thickness. This graphite is outgassed at $850^{\circ} \mathrm{C}$ for two days. The metal halides are distilled first under vacuum, and secondly under a chlorine atmosphere. Intercalation is carried out in the classical "two bulb" tube, under a chlorine atmosphere in a two temperature oven. All compounds studied were first stage where all galleries are filled with intercalant and the reaction conditions used for their synthese are given in table $\mathrm{I}$.

Table I. - Conditions used for the intercalation of the single crystals.

\begin{tabular}{|l|c|c|c|c|}
\hline $\mathrm{MCl}_{x}$ & $T_{\text {graphite }}\left({ }^{\circ} \mathrm{C}\right)$ & $T_{\text {halide }}\left({ }^{\circ} \mathrm{C}\right)$ & Reaction time & $P_{\text {chlorine }}($ atm $)$ \\
\hline $\mathrm{FeCl}_{3}$ & 300 & 295 & 2 days & 2 \\
\hline $\mathrm{CoCl}_{2}$ & 585 & 580 & 15 days & 12 \\
\hline
\end{tabular}

The intercalation compound is transferred under inert atmosphere, a small part being placed in an air-tight sample holder for X-ray characterization. The remainder is laid in a Pyrex glass reactor. Alkali metal is placed under argon in the same reactor and distilled beside the G.I.C. The evacuated and sealed reactor is put in a furnace with a small temperature gradient to allow vapour phase reaction. Most of the reductions are carried out at $100^{\circ} \mathrm{C}$ for one (Cs) to four weeks (K). After reaction the average chemical formula is $\mathrm{C}_{5.8} \mathrm{Fe}(\mathrm{MCl})_{3} \mathrm{M}_{0.9}$. Since the reduction products occupy less than the total gallery volume, the remainder is filled with alkali metal $\left(\mathrm{MC}_{8}\right.$ phase). After reaction, the product is left overnight in an argon atmosphere containing $10-100$ ppm oxygen to permit diffusion and slow oxidation of the excess alkali metal at the edges of the crystals. The particles are dispersed in alcohol, filtered through a Nuclepore filter covered with evaporated amorphous carbon. Another layer of carbon is further evaporated on the sample. A small part is cut off and placed on a microscope grid and the polymer membrane is dissolved with its specific solvent $\left(\mathrm{CHCl}_{3}\right)$. So, the graphene layers are parallel to the grid plane. S.E.M. observation of the 
particles shows little deformation of the single crystals. For direct imaging and microdiffraction a Jeol 200 CX T.E.M. was used. Microanalysis was performed on the Varian high vacuum S.T.E.M. at the University of Orsay (France).

Several kinds of samples were studied:

- as reduced products containing iron or cobalt;

- $\mathrm{G}-\mathrm{FeCl}_{3}$ compounds reduced by $\mathrm{Cs}$ at $100^{\circ} \mathrm{C}$ and heated at $580^{\circ} \mathrm{C}$ in situ in the T.E.M.;

- $\mathrm{G}-\mathrm{FeCl}_{3}$ compounds reduced by $\mathrm{K}, \mathrm{Rb}$ or $\mathrm{Cs}$ at $100^{\circ} \mathrm{C}$ and further annealed at $730^{\circ} \mathrm{C}$.

\section{Results.}

3.1 As REDUCED PRODUCTS. ( $\mathrm{G}-\mathrm{FeCl}_{3}$ REDUCED AT $100^{\circ} \mathrm{C}$ BY $\mathrm{K}, \mathrm{Rb}$ OR $\mathrm{Cs}$ AND $\mathrm{G}-\mathrm{CoCl}_{2}$ REDUCED AT $100^{\circ} \mathrm{C}$ BY Cs).

3.1.1 Bright field magnification pictures. - Direct imaging reveals the complexity of the samples: all of them are constituted of three types of zones, the area of each depending on the reducing agent and the reduction conditions. These three types of zones are:

- "clear zones", where the density of the sample is lower. They are visible on all pictures of figure 1 and correspond to pure graphite areas: the reaction products occupy less gallery space than the starting iron trichloride;

- uniformly "grey" areas, visible in figure $1 \mathrm{a}$ relative to a $\mathrm{G}-\mathrm{FeCl}_{3}$ compound reduced by cesium at $100^{\circ} \mathrm{C}$. These domains are much wider in cesium reduced products and contain few three dimensional microcrystals. They will be shown to be constituted of two dimensional species;

- clusters area, present on figure $1 \mathrm{~b}$ and $1 \mathrm{c}$, corresponding to products reduced by rubidium and potassium at $100^{\circ} \mathrm{C}$. These zones have a greater extent for the lighter reducing agent $(\mathrm{K})$. These domains contain many three dimensional clusters with various shapes and sizes, ranging between 5 and $50 \mathrm{~nm}$.

3.1.2 Microanalysis. - Figure 2 presents on all spectra the line of copper due to the microscope grid, and several small peaks corresponding to residual impurities of the natural single crystals of graphite, such as silicon. Microanalysis relative to the uniformly "grey" areas in figure 2 a shows the existence of a significant quantity of iron, and some chlorine and cesium. As the observation at high magnification does not reveal any three dimensional crystallite, iron and alkali metal chloride are present as two dimensional domains between the layers. Under the electron beam, the two dimensional alkali metal chloride seems to become somewhat mobile. Measuring the chlorine line for a long time allows determining that this species does not escape from the sample and remains encapsulated between the graphene layers.

Figure $2 \mathrm{~b}$ presents the microanalysis of a cluster area in $\mathrm{a} \mathrm{G}-\mathrm{FeCl}_{3}$ compound reduced by $\mathrm{K}$ at $100^{\circ} \mathrm{C}$ (Fig. 1c). This domain contains iron and alkali metal chloride. We have applied the microanalysis to individual clusters, as shown in figure $2 \mathrm{c}$ relative to an included iron cluster. Such nodules are constituted either of iron or of alkali metal chloride, irrespective of their shapes, sizes or appearence. Excess of alkali metal is removed by oxidation, but by chance we found a separating zone in which alkali metal remained (Fig. 2d) showing that this excess alkali metal is a pure first stage Cs G.I.C. and does not alloy to iron.

3.1.3 High resolution lattice imaging. - Some crystals present folded edges, and there the graphene layers can be parallel to the beam, favouring observation in the $\overrightarrow{\mathbf{c}}$ direction. Figure 3 shows a side view of a cluster included between the layers: the graphene sheets are bent around the cluster. These lenticular nodules are roughly five times longer than they are thick.

In the case of $\mathrm{G}-\mathrm{FeCl}_{3}$ compounds reduced at $100^{\circ} \mathrm{C}$ by cesium, intercalated iron domains have been seen (Fig. 4). The domain presented here is roughly $20 \mathrm{~nm}$ in width and is four layers 


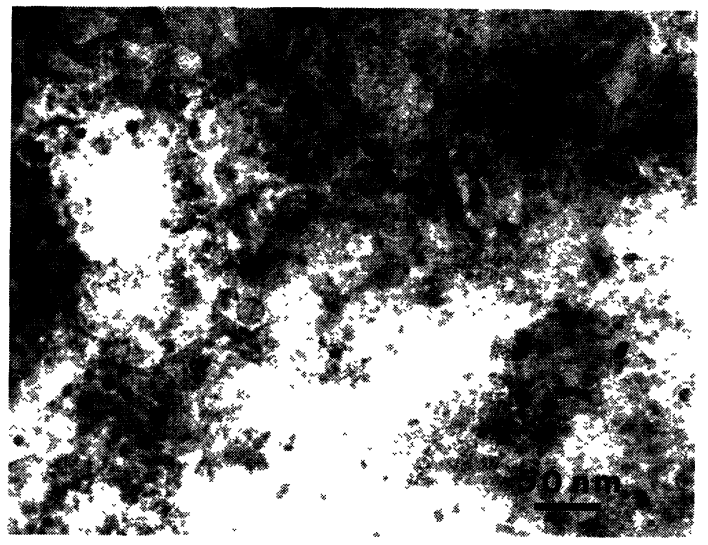

a)

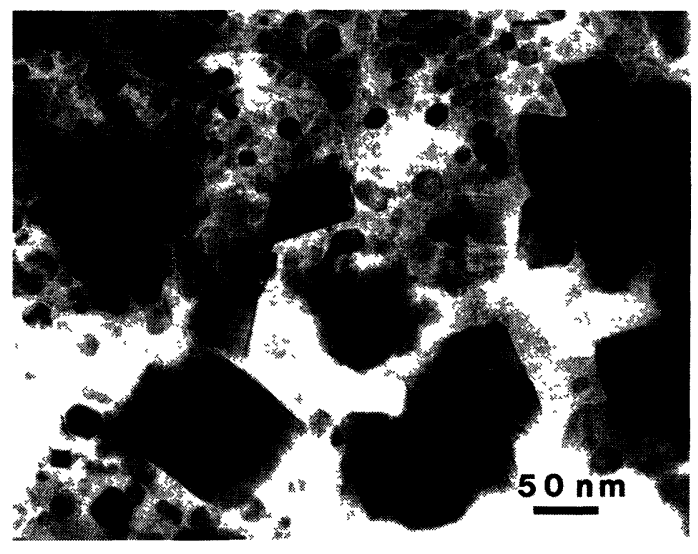

b)

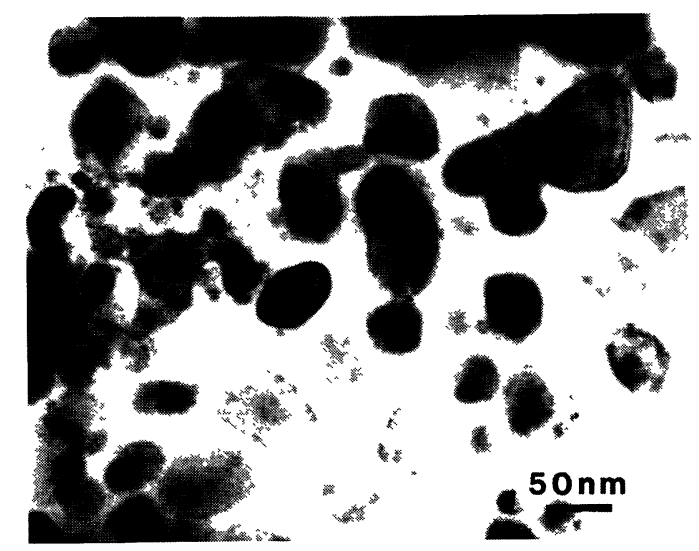

c)

Fig. 1. - Bright field T.E.M. image from $\mathrm{G}-\mathrm{FeCl}_{3}$ compound reduced at $100^{\circ} \mathrm{C}$ by a) $\left.\mathrm{Cs} \mathrm{b}\right) \mathrm{Rb}$ c)K.

thick. These dimensions are representative. The interplanar distance is about $500 \mathrm{pm}$ and the distance between atomic columns in the plane is $490 \mathrm{pm}$. The $\mathrm{c}$ axis stacking is $\mathrm{A} / \mathrm{B} / \mathrm{C}$.

3.1.4 Electron microdiffraction. - Microdiffraction on the single crystals was carried out with the beam perpendicular to the carbon layers, allowing $h k 0$ observation. The $h k 0$ reflexions of graphite, present on all diagrams were used as internal standards for calibration. Microdiffraction of selected areas was applied to the various zones.

- When the diffracting volume is limited to a "clear area", only the $h k 0$ spots of graphite are present.

- In the cluster areas, the diagrams show all the reflexions of the transition metal ( $\alpha$ cobalt or $\alpha$ iron) and of the alkali metal chloride. All of them appear as randomly punctuated rings.

- Diagrams from the "grey" zones are strongly dependent on the reducing agent. The results for each reducing agent will be successively described in the following.

Cesium. - The diffraction diagram in figure 5 is relative to a compound $\mathrm{G}-\mathrm{FeCl}_{3}$ reduced by cesium at $100^{\circ} \mathrm{C}$. The strong $h k 0$ reflexions of graphite are present with their hexagonal symmetry. The other reflexions are due to cesium chloride or iron. 

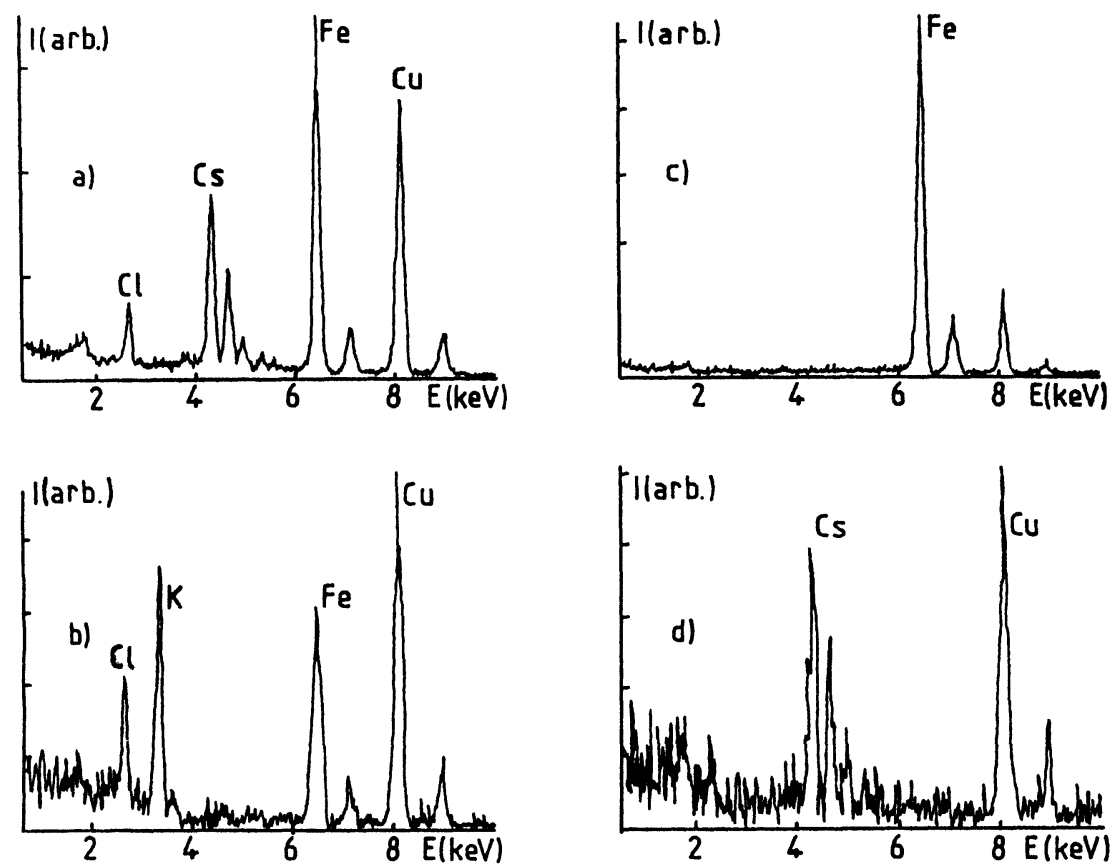

Fig. 2. - Microanalysis spectra of $\mathrm{G}-\mathrm{FeCl}_{3}$ compound reduced at $100^{\circ} \mathrm{C}$ by a) $\mathrm{Cs}$ ("grey" area) b) $\mathrm{K}$ (cluster area) c) Cs (single cluster of included iron) d) Cs (zone containing only Cs).

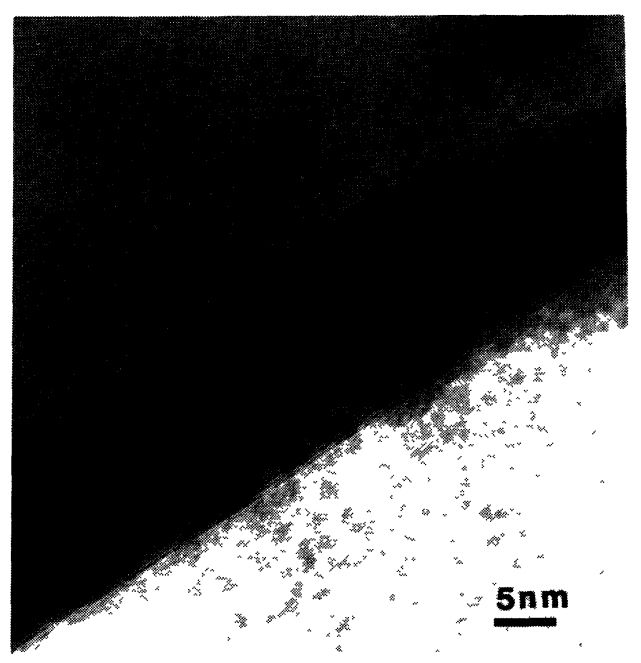

Fig. 3. - Side view of a cluster included between the graphene layers.

All $h k l$ reflexions of cesium chloride are present as nearly continuous rings corresponding to three dimensional crystallites randomly distributed with respect to the graphite lattice. However, 


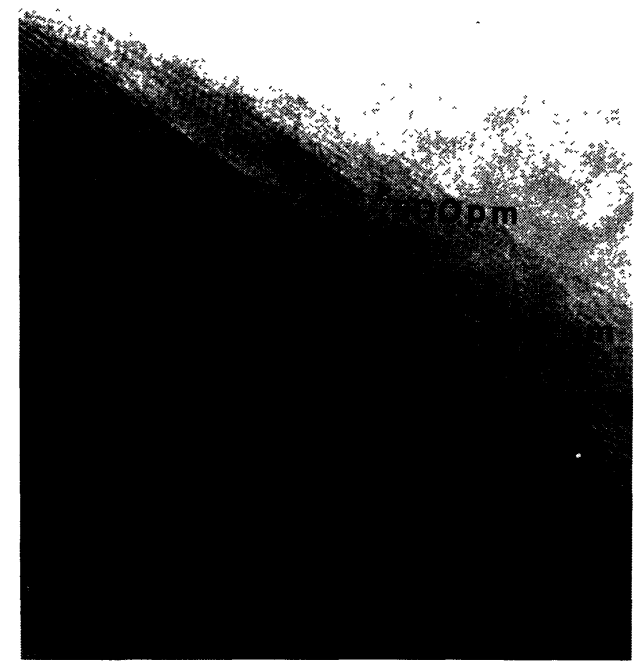

Fig. 4. - High resolution lattice imaging of the intercalated iron phase $(a=492 \mathrm{pm})$ at the edge of a particle reduced by Cs.

twelve reinforcements appear on the $h k 0$ rings. On the $h 00$ rings, these spots are situated on the direction common to (100) or (110) spots of graphite, whereas those on the rings (110) and (220) of $\mathrm{CsCl}$ are rotated $\pm 15^{\circ}$ with respect to the previous. These twelve spots, separated by $30^{\circ}$ on their ring, can be explained by the existence of three domains rotated with respect to each other by $120^{\circ}$, due to the hexagonal symmetry of the planar graphene lattice. The cubic lattices of that $\mathrm{CsCl}$ crystallites have their basal planes parallel to the graphene sheets and the other faces oriented with respect to the in-plane graphite axes by $0^{\circ}$ or $\pm 15^{\circ}$.

The spots belonging neither to graphite nor to cesium chloride have been attributed to iron intercalated between the layers. A series of weak rings on which are superimposed 12 arcs of strong intensity $\left(10^{\circ}\right.$ width) has been attributed to two dimensional iron. The corresponding distances can be indexed in a square lattice. The multiplicity of twelve is explained by the existence of three square lattices rotated by $120^{\circ}$ with respect to each other. The first set of 12 spots (starting from the center) has been indexed as (10) reflexions of the square lattice, leading to a square lattice in plane parameter of $348 \mathrm{pm}$. These spots are rotated $\pm 15^{\circ}$ with respect to the (100) and (110) graphite spots. The second set of 12 spots is indexed as (11) being rotated $\pm 15^{\circ}$ with respect to the previous and are then collinear with the graphite lattice spots (100) or (110).

Some diagrams, corresponding to areas situated on the edges of the particles, can show another ring also with 12 spots. The corresponding reticular distance is $492 \mathrm{pm}$ which is close to the in-plane distance given by the high resolution lattice imaging. The spot orientation and the reticular distance $(\sqrt{2} \times$ square lattice parameter above) show that these reflexions belong to another square lattice, rotated $\pm 45^{\circ}$ with respect to the previous. This latter lattice is commensurate with the graphite lattice along one direction. It is present only in small quantities, mainly near the edges of the graphite particles where the iron chloride can escape during the reduction, giving a less dense iron lattice.

The diagram in figure 6 is relative to a compound $\mathrm{G}-\mathrm{CoCl}_{2}$ reduced by cesium at $100^{\circ} \mathrm{C}$. It is comparable to that of figure 5 and shows reflexions of the graphite lattice, cesium chloride, $\alpha$ cobalt and two dimensional cobalt. We find here the same system of randomly distributed and oriented cesium chloride crystals, with the same orientation as in the previous system. 


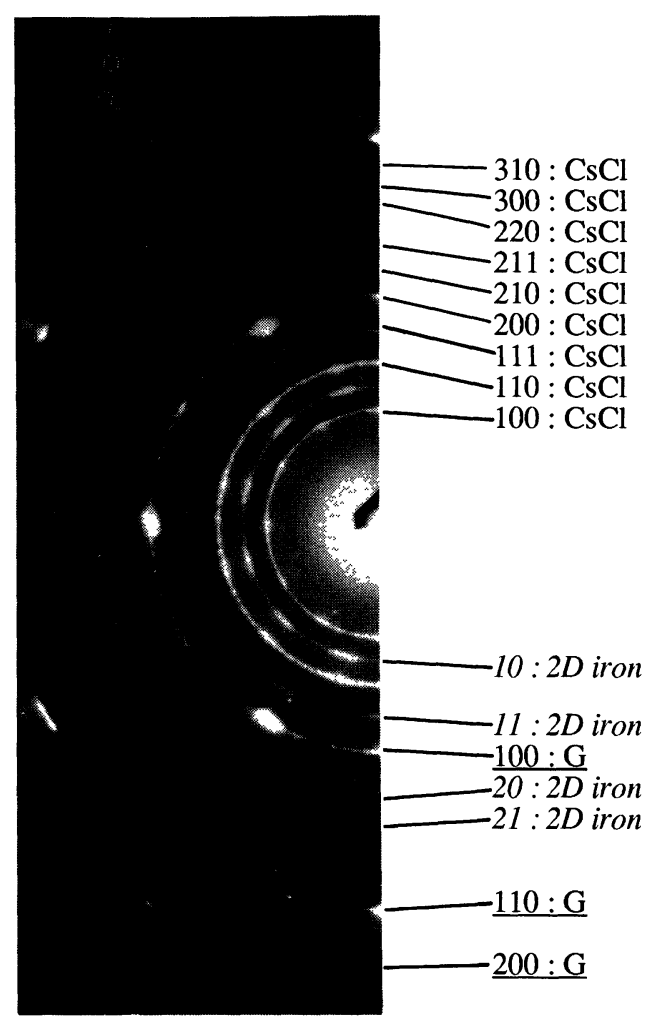

Fig. 5. - Selected area electron diffraction diagram of a $\mathrm{G}-\mathrm{FeCl}_{3}$ compound reduced by $\mathrm{Cs}$ at $100^{\circ} \mathrm{C}$.

The rings corresponding to the $\alpha$ cobalt are very weak and quite continuous, the $\alpha$ cobalt crystallites having no preferred orientation with respect to the graphite lattice. They represent only a small portion of the cobalt contained in the sample.

A set of weak rings with twelve strong reinforcements is attributed to two dimensional cobalt. Reticular distances and orientations of the spots permit their indexing in a square lattice of parameter $348 \mathrm{pm}$ analogous to that previously described for iron. Cobalt lattices also form three domains rotated $\pm 120^{\circ}$ with respect to each other and whose a directions are at $\pm 15^{\circ}$ with respect to that of graphite.

Rubidium. - The diffraction diagram of figure 7 is relative to a compound $\mathrm{G}-\mathrm{FeCl}_{3}$ reduced by rubidium at $100^{\circ} \mathrm{C}$. As in the previous cases, the graphite particle remains a single crystal. Among the reflexions of rubidium chloride, the $h k 0$ rings alone appear. The cubic lattices of $\mathrm{RbCl}$ have their basal planes parallel to the graphene layers. These rings have twelve reinforcements oriented with respect to the graphite spots: those on the (220) and (440) rings are in the directions of the (100) or (110) graphite spots; the reinforcements on the (200) and (400) are rotated $\pm 15^{\circ}$ with respect to the previous. As for $\mathrm{CsCl}$ three domains also exist, the three axes of them being also oriented with respect to the graphite axes. The difference is a rotation of $15^{\circ}$ in the a,b plane of graphite between $\mathrm{RbCl}$ and $\mathrm{CsCl}$.

A series of weak, but nearly continuous rings is due to the presence of three dimensional $\alpha$ iron crystallites. Other iron phases are visible:

- A series of rings with twelve reinforcements has been attributed to a square, two dimensional 


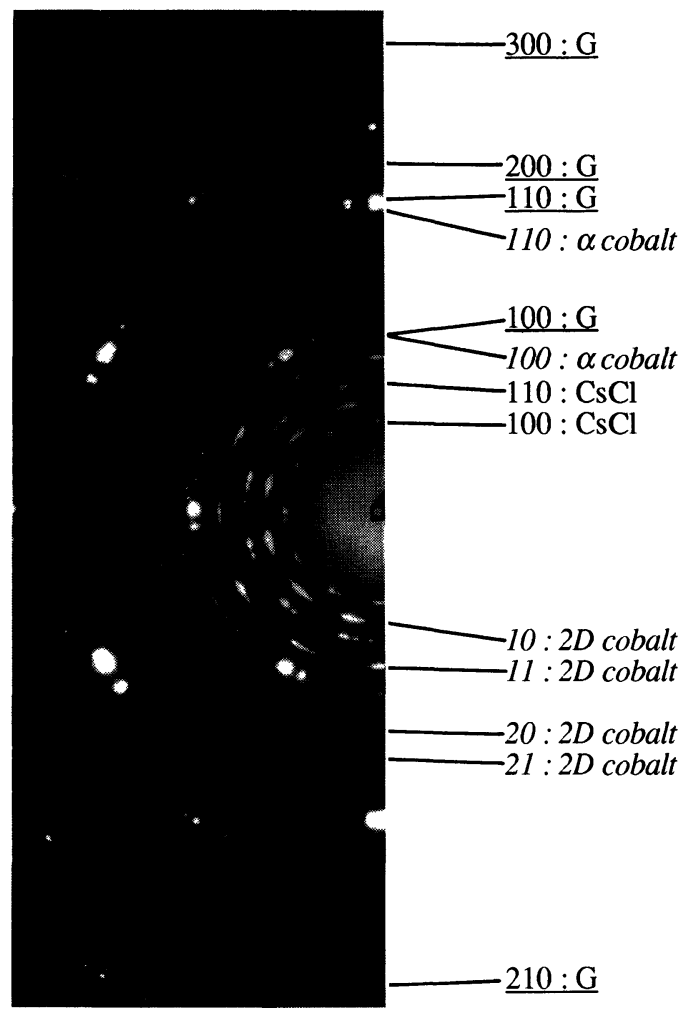

Fig. 6. - Selected area electron diffraction diagram of a $\mathrm{G}-\mathrm{CoCl}_{2}$ compound reduced by $\mathrm{Cs}$ at $100^{\circ} \mathrm{C}$.

iron phase, the parameter of which is $410 \mathrm{pm}$. This lattice is rotated $\pm 15^{\circ}$ with respect to the square iron lattice ( $348 \mathrm{pm})$ existing in the products reduced by Cs.

- A set of spots has been indexed in a hexagonal lattice with a parameter $a=252 \mathrm{pm}$.

Potassium. - Figure 8 shows the diffraction diagram of a compound $\mathrm{G}-\mathrm{FeCl}_{3}$ reduced by potassium at $100^{\circ} \mathrm{C}$. As in the previous case, as concerns the alkali metal chloride, only the $h k 0$ reflexions are visible, appearing as continuous rings. The basal planes of that crystallites are parallel to the graphite layers, but there is no orientation with respect to the a,b axes of graphite.

$\alpha$ iron is present in the sample and gives a set of rings of low intensity.

Another set of spots has been attributed to two dimensional iron and indexed in a hexagonal lattice, the parameter of which is $353 \mathrm{pm}$.

3.2 INFLUENCE OF REDUCTION TEMPERATURE AND DURATION. - T.E.M. observation of numerous particles shows that the increase of the reduction temperature and duration have the same effects: the quantity and the size of three dimensional clusters both rise.

If the reduction of the compound $\mathrm{G}-\mathrm{FeCl}_{3}$ by cesium is carried out at $50^{\circ} \mathrm{C}$, the organization of two dimensional iron and cesium chloride phases is poorer than in the products reduced at $100^{\circ} \mathrm{C}$. Some diagrams show a small quantity of $\mathrm{G}-\mathrm{FeCl}_{3}$ compounds: the reduction reaction is not always complete at this temperature.

At a reduction temperature of $100^{\circ} \mathrm{C}$ and above, no evidence is found of ferric chloride: the reduction is complete [7]. 


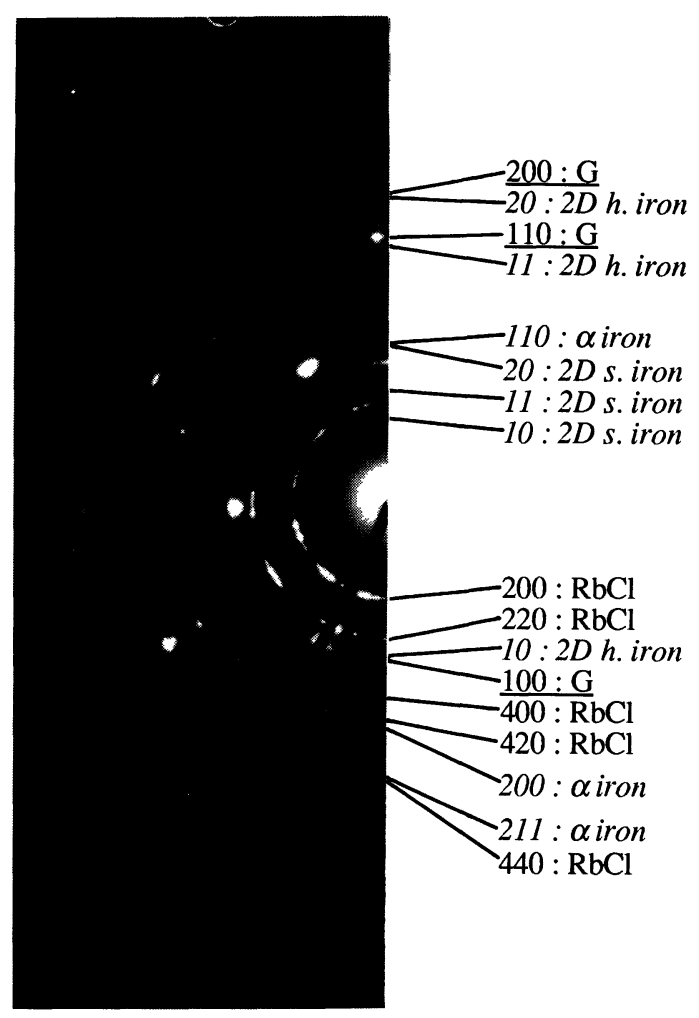

Fig. 7. - Selected area electron diffraction diagram of a $\mathrm{G}-\mathrm{FeCl}_{3}$ compound reduced by $\mathrm{Rb}$ at $100^{\circ} \mathrm{C}$.

At a reduction temperature of $200^{\circ} \mathrm{C}$ no change is visible on the diffraction diagrams with respect to that of products reduced at $100^{\circ} \mathrm{C}$.

At a reduction temperature of $300^{\circ} \mathrm{C}$ there is a clear evolution:

- all observable reflexions of $\alpha$ iron are present;

- some alkali metal chloride remains oriented with respect to the graphite lattice, but the occurence of $h \mathrm{kl}$ reflexions reveals the presence of randomly oriented crystallites;

- in the case of compounds reduced by rubidium, finely punctuated rings could be due to an iron carbide $\left(\varepsilon \mathrm{Fe}_{2} \mathrm{C}\right)$.

3.3 IN SITU HIGH TEMPERATURE T.E.M. OBSERVATION OF $\mathrm{G}-\mathrm{FeCl}_{3}$ REDUCED AT $100^{\circ} \mathrm{C}$. The use of a heating sample holder permits the observation of the changes of the diffraction diagram with temperature. The room temperature (R.T.) diagram is that of figure 5.

At $350^{\circ} \mathrm{C}$ the diagram is little modified: in plane reticular distances of graphite are not significantly changed, due to its low thermal coefficient of expansion, but that of $\mathrm{CsCl}$ and two dimensional iron have risen. All along the heating, the orientation of the phases weakens.

At $580^{\circ} \mathrm{C}$ (Fig. 9) the diagram is somewhat changed. This is attributed to the fact that at $445^{\circ} \mathrm{C}$, $\mathrm{CsCl}$ takes on the f.c. $\mathrm{NaCl}$ structure. A few reflexions of the cubic $\mathrm{CsCl}$ structure remain visible, but the lattice constant has expanded from $412 \mathrm{pm}$ to $435 \mathrm{pm}$. Some rings of the f.c. $\mathrm{CsCl}$ phase are superimposed on that of two dimensional iron, but that iron phase remains present: the (20) ring is clearly visible. The superimposed spots remain, but weaker than at R.T., indicating the 


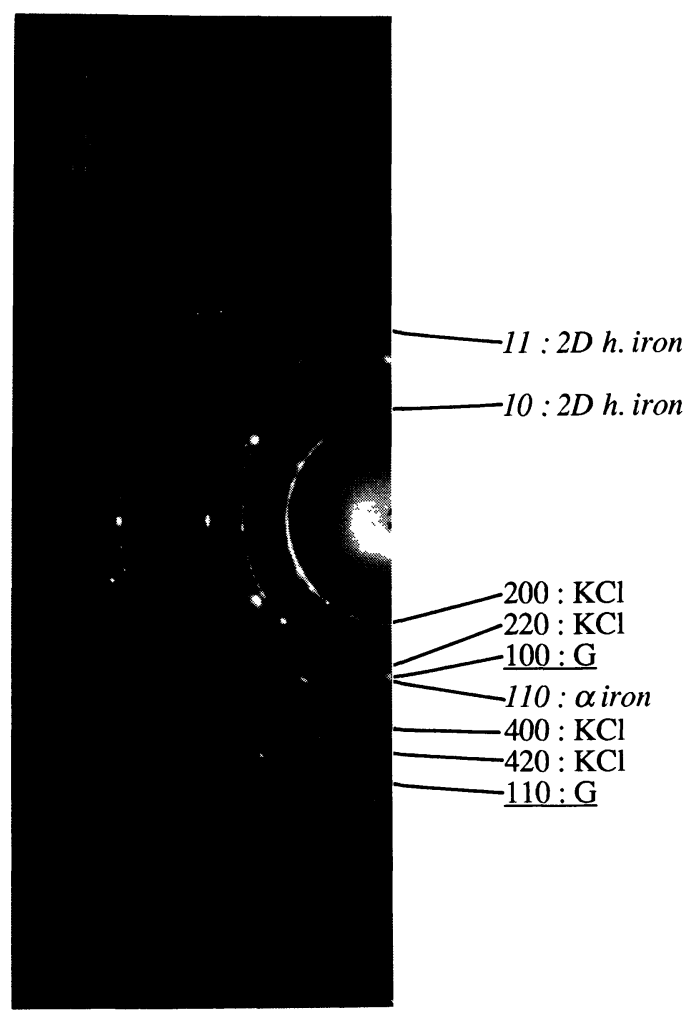

Fig. 8. - Selected area electron diffraction diagram of a $\mathrm{G}-\mathrm{FeCl}_{3}$ compound reduced by $\mathrm{K}$ at $100^{\circ} \mathrm{C}$.

persistence of some orientational order. However the reticular distances are expanded to $355 \mathrm{pm}$, leading to a coefficient of thermal expansion between 20 and $580^{\circ} \mathrm{C}$ of $36 \times 10^{-6} \mathrm{~K}^{-1}$.

Randomly oriented $\alpha$ iron begins to appear, but only a small quantity of two dimensional iron has disappeared.

3.4 ANNEALED PRODUCTS. - Compounds $\mathrm{G}-\mathrm{FeCl}_{3}$ reduced by $\mathrm{K}, \mathrm{Rb}$ or $\mathrm{Cs}$ at $100^{\circ} \mathrm{C}$ were annealed at $730^{\circ} \mathrm{C}$ in a sealed ampule for several hours.

3.4.1 Bright field magnification pictures. - Figure 10 , relative to a compound $\mathrm{G}-\mathrm{FeCl}_{3}$ reduced at $100^{\circ} \mathrm{C}$ by $\mathrm{Cs}$ and further annealed at $730^{\circ} \mathrm{C}$ shows large changes. The graphite particles present zones of low density much larger than before heating, surrounded by darker areas with numerous clusters, up to $500 \mathrm{~nm}$ in diameter. In the case of the compounds reduced by $\mathrm{Rb}$ or $\mathrm{Cs}$, the melting point of the halide has been attained, multiplying its mobility. The alkali metal halide has coalesced, leaving free graphite areas, and has recrystallized as bigger clusters, in particular at the edges of the particles. The "grey" zones without clusters are of smaller surface areas and three dimensional clusters are visible on most of the surface, part of the two dimensional iron having transformed to $\alpha$ iron.

\subsubsection{Electron microdiffraction.}

- Products reduced by cesium. - The diagram of figure 11 is relative to a compound $\mathrm{G}-\mathrm{FeCl}_{3}$ reduced by $\mathrm{Cs}$ at $100^{\circ} \mathrm{C}$ and further annealed at $730^{\circ} \mathrm{C}$. The reflexions of graphite, 


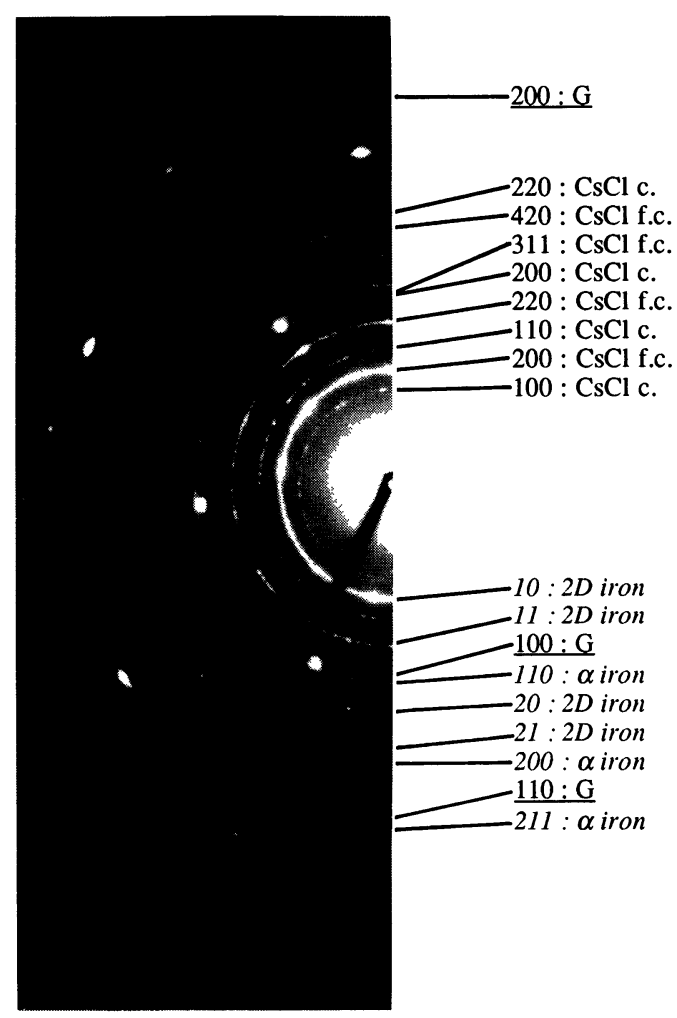

Fig. 9. - Selected area electron diffraction diagram of a G $-\mathrm{FeCl}_{3}$ compound reduced by $\mathrm{Cs}$ at $100^{\circ} \mathrm{C}$ and heated in situ in the microscope to $580^{\circ} \mathrm{C}$.

cesium chloride and two dimensional iron are present, but the preferential orientations of the last two phases have disappeared. The cesium chloride, on cooling, has recrystallized as big randomly distributed clusters, as shown by the small spots forming the diffraction rings, and also revealed by imaging.

The two dimensional iron phase persists, despite the loss of orientation. This phase is then quite thermally stable.

The $\alpha$ iron rings are finely punctuated, of much stronger intensity than in as - reduced products. The annealing causes the partial conversion of two dimensional iron to $\alpha$ iron.

- Products reduced by rubidium. - The evolution of the products is similar to that reduced by cesium. However some differences can be pointed out: the rubidium chloride maintains part of its orientation with respect to the graphite lattice. The two dimensional iron phases present in as-reduced products have disappeared, converted to $\alpha$ iron or to the square two dimensional iron phase contained in products reduced by cesium, the parameter of which is $348 \mathrm{pm}$.

- Products reduced by potassium. - The evolution is somewhat similar to the other systems, except that potassium chloride is, in some particles, oriented after annealing. $\alpha$ iron is present in large quantities. The hexagonal, two dimensional iron phase $(a=353 \mathrm{pm})$ has been transformed into the square iron lattice, the parameter of which is $348 \mathrm{pm}$ (present in the products reduced by cesium). Apart from the reflexions corresponding to these phases, the diagram possesses a series 


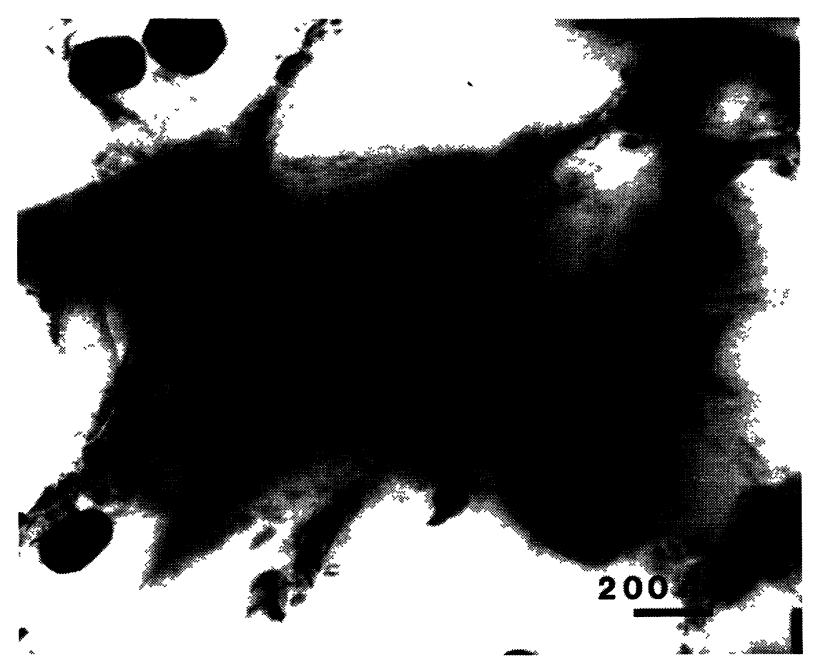

Fig. 10. - Bright field T.E.M. image from $\mathrm{G}-\mathrm{FeCl}_{3}$ compounds reduced at $100^{\circ} \mathrm{C}$ by $\mathrm{Cs}$ and further annealed at $730^{\circ} \mathrm{C}$.

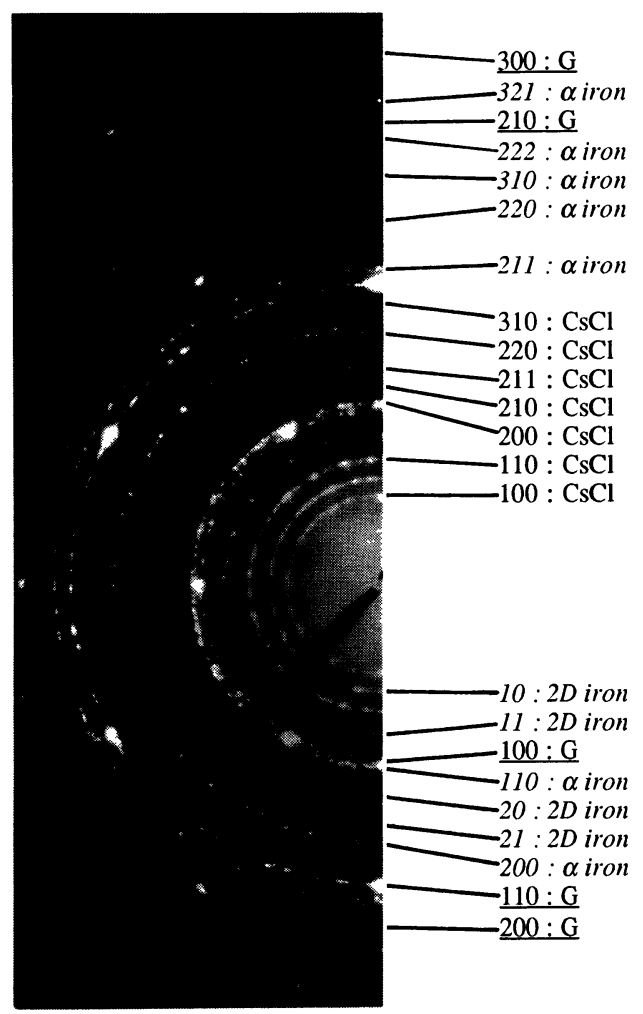

Fig. 11. - Selected area electron diffraction diagram of a $\mathrm{G}-\mathrm{FeCl}_{3}$ compound reduced by $\mathrm{Cs}$ at $100^{\circ} \mathrm{C}$ and further annealed at $730^{\circ} \mathrm{C}$. 
of spots, the indexing of which remains unclear. They could be due to hexagonal iron carbide phases formed during annealing.

\section{Conclusion.}

Alkali metal vapour is a good reducing agent for intercalated halides. It has the advantages of intercalating into graphite, favoring by in situ reaction the formation of intercalation compounds or included metallic clusters. It has also the advantage that the excess reactant is able to deintercalate under mild conditions without distorting the layers, helping to maintain the crystallinity of the starting material. The initial step is always the escape of a very small quantity of halide, depending on the temperature, which is reduced by the alkali metal vapour, forming clusters at the edges of the particles. Intercalation can then proceed.

The use of electron microscopy, microdiffraction and microanalysis has been essential in the identification of the exact nature of the different phases present in the particles: pure graphite, crystals of alkali metal halide (oriented or not), two dimensional intercalated metal and three dimensional metal clusters. Most of these phases, located between the layers can resist washing with boiling hydrochloric acid.

For all products the influence of a longer time or a higher temperature of reduction is the same: the size and the quantity of three dimensional clusters increase and the quantity of two dimensional metal is reduced. This could be due to a diffusion process of the metal from the intercalated layers to the thermodynamically more stable three dimensional clusters. This diffusion could take place through the alkali metal filling the voids in the graphite particles and such evolution is suppressed by removing the excess alkali metal. This can explain that products reduced by $\mathrm{K}$ always contain a higher percentage of clusters, due to the longer reaction times imposed by lower $\mathrm{K}$ vapour pressure.

The exact nature of the reducing agent is of major importance for the abundance and exact nature of the two dimensional metal phases. Reducing first stage $\mathrm{G}-\mathrm{FeCl}_{3}$ or $\mathrm{G}-\mathrm{CoCl}_{2} \mathrm{com}$ pounds by $\mathrm{Cs}$ gives the same square lattice for both intercalated metals. So we used several heavy alkali metals to reduce $\mathrm{G}-\mathrm{FeCl}_{3}$ compounds in the same temperature conditions and have obtained different phases. Reduction by $\mathrm{Cs}$ gives square intercalated metal phases, reduction by $\mathrm{Rb}$ both square and hexagonal metal phases whereas reduction by potassium gives only a hexagonal metal phase. Meyer et al. [8] by chemical reduction with n-butyl lithium also obtained a hexagonal metal phase $(a=415 \mathrm{pm})$, whereas electrochemical reaction [9] resulted in a tetragonal lattice $(a=282 \mathrm{pm})$. Chemical reductions with light alkali metals seem to give hexagonal intercalated iron lattices and there is an evolution to square lattices for heavier alkali metals.

Annealing of Cs-reduced products has shown some segregation of the phases but the major fact is the conversion of most two dimensional metal phases to that with a square lattice $(a=348 \mathrm{pm})$, which persists up to $730^{\circ} \mathrm{C}$ and is consequently the more stable. We present the hypothesis that the graphene layers influence on the metal layer formation depends on the size of the reducing metal. When the metal is small, the layers are not widely spread apart and the graphene layer will force the metal to assume an hexagonal structure. When the metal is bigger, the layers are sufficiently separated to allow the formation of more stable square lattices.

\section{Acknowledgements.}

We wish to express our grateful thanks to Professor C. Colliex, of the Laboratoire de Physique des Solides de l'Université de Paris Sud (Orsay) for the use of its S.T.E.M. and help in the microanalysis measurements and interpretations. 


\section{References}

[1] SAUNDERS K.G. and FrYeR J.R., Proc. Int. Carbon and Graphite Conf. (London, G.B.) vol.2 (1978) 738.

[2] SMITH D.J., FISHER R.M. and FREEMAN L.A., J. Catal 72 (1981) 51.

[3] NGUESSAN G.K. and TOUZAIN PH., Proc. Int. Coll. on Layered Compounds (Pont-à-Mousson, France) D. Guérard and P. Lagrange Eds. (1988) p.137.

[4] NGUESSAN G.K. and TOUZAIN PH., Synth. Met. 34 (1989) 267.

[5] MESSAOUdi A., ERRE R. and BEgUIN F., Proc. Int. Coll. on Layered Compounds (Pont-à-Mousson, France) D. Guérard and P. Lagrange Eds. (1988) p.77;

KAISER P., MessaOUdi A., Bonnin D., ERRE R. and BEguin F., J. Chim. Phys. 86 (1989) 1787;

MESSAOUdI A., ERRE R. and BEGUIN F., Carbon 29 (1991) 515.

[6] MABChOUR A., Furdin G. and MARECHE J.-F., C.R. Acad. Sci. Paris. Série II 312 (1991) 1293.

[7] HEROLD C., MARECHE J.-F., GERARDIN R., MABCHOUR A. and FURDIN G., Mat. Res. Bull. 27 (1991).

[8] Meyer C., Yazami R. and Chouteau G., J. Phys. France 51 (1990) 1239.

[9] TOUZAIN PH., ChAMBEROD A., BRIGgs A., Mater. Sci. Eng. 31 (1977) 77.

[10] FORSTNER A., HOFER F., WEIDMANN H., Carbon 29 (1991) 915. 